\title{
Capital humano e desigualdade salarial no Brasil: uma análise de decomposição para o período 1995-2014
}

\author{
Vitor Hugo Miro Couto Silva \\ Professor - Universidade Federal do Ceará (UFC- Campus de Sobral) \\ Endereço: Rua Coronel Estanislau Frota, s/n - Centro - Sobral/CE \\ CEP 62010-560 - E-mail: vitormiro@gmail.com
}

\author{
João Mário Santos de França \\ Professor - Universidade Federal do Ceará (UFC-CAEN) \\ Endereço: Avenida da Universidade, $2700-2^{\circ}$ Andar - Benfica - Fortaleza/CE \\ CEP 60020-181 - E-mail: joao.franca@ufc.br
}

\author{
Valdemar Rodrigues de Pinho Neto \\ Doutorando - Fundação Getúlio Vargas (EPGE-FGV) \\ Endereço: Rua Praia de Botafogo, 190 - Botafogo - Rio de Janeiro/RJ \\ CEP 22250-900 - E-mail: valdemar.neto@fgvmail.br
}

Recebido: 12/03/2015. Aceito 21/05/2016.

\section{Resumo}

Este artigo investiga fatores que podem explicar a redução da desigualdade salarial no Brasil entre 1995 e 2014, utilizando um método sugerido por Yun (2006). Este método corresponde a uma junção de outras duas formas de decomposição: Juhn Murphy e Pierce (1993) e Fields (2003). A aplicação conjunta dessas metodologias proporciona um maior nível de detalhamento no exercício de decomposição, ao permitir obter os efeitos preço e quantidade associados a cada uma das variáveis explicativas da equação de salários. Os resultados encontrados, com base nos dados da PNAD, mostram que a recente queda da desigualdade salarial foi devida, essencialmente, à acumulação de capital humano, enquanto fricções no mercado de trabalho (segmentação e discriminação) parecem ter desempenhado um papel secundário nesse processo. O efeito preço associado ao capital humano foi o principal responsável por essa redução e, em particular, a queda dos retornos educacionais teve papel de destaque nesse resultado.

\section{Palavras-Chave}

Desigualdade salarial. Decomposição da desigualdade. Regressão de salários.

\begin{abstract}
This paper investigates factors that may explain the reduction in wage inequality in Brazil between 1995 and 2014 using a decomposition method suggested by Yun (2006). This method is a synthesis of two another methods, a decomposition proposed by Juhn, Murphy and Pierce (1993) and the other was suggested by Fields (2003). The application of these methods provides a greater level of detail in the decomposition exercise by allowing get the price and quantity effects associated with each of the explanatory variables in the wage equation. The results based on PNAD data, shows that the recent decline in the wage inequality was due mainly to the human capital accumulation, while frictions in the labor market (segmentation and discrimination) seem to have played a secondary role in this process. The price effect associated with human capital was the main reason for this reduction and, in particular, the fall in returns to education played an important role in this result.
\end{abstract}




\section{Keywords}

Wage inequality. Decomposition of inequality. Wage regression.

\section{JEL Classification}

J31. D31.

\section{Introdução}

Após relativa estabilidade durante a segunda metade da década de 1990, a desigualdade de renda no Brasil declinou de forma acentuada ao longo da década de 2000. Diversos estudos apontam para a significância dessa redução e para os fatores que ajudam a explicar esse fenômeno. ${ }^{1}$ Dentre estes trabalhos, Barros et al. (2010) mostram que o grau de desigualdade de renda entre 2001 e 2007 declinou de forma acentuada e contínua. O coeficiente de Gini declinou 7\% no período (0,593 em 2001 para 0,552 em 2007), atingindo o menor valor dos últimos 30 anos. Os autores também comentam que, de 74 países para os quais se tem informações sobre a evolução do coeficiente de Gini, em menos de $25 \%$ deles houve redução semelhante e de mesma magnitude. Essa tendência de redução do índice de desigualdade foi observada nos anos seguintes, com o coeficiente de Gini atingindo o valor de 0,518 em 2014, o menor valor da série histórica até então.

Mesmo após esse acentuado declínio, a desigualdade de renda brasileira permanece extremamente elevada. Barros et al. (2010) apontam que cerca de $90 \%$ dos países ainda apresentam distribuições menos concentradas que a do Brasil, o que indica a necessidade de um processo de redução da desigualdade de renda contínuo e sustentável até patamares mais baixos. Sob a égide desse argumento, a dinâmica da desigualdade de renda no Brasil ainda permanece como um importante tema de pesquisa e sua análise merece atenção permanente, não apenas do meio acadêmico, mas também político.

O declínio da desigualdade de renda nos primeiros anos da década de 2000 recebeu bastante atenção na literatura recente. Uma das principais abordagens sobre o tema se ocupou da análise de fatores

1 Além de significante no sentido comum, pela magnitude e velocidade da redução; a significância estatística da redução da desigualdade na primeira metade dos anos 2000 foi testada por Azevedo (2007). 
determinantes da redução da desigualdade, sejam eles componentes da renda como em Soares (2006), Soares et al. (2006), Hoffmann (2006) e Hoffmann e Oliveira (2014), ou determinantes imediatos ${ }^{2}$ como os definidos em Barros et al. (2006), Barros et al. (2007a) e Barros et al. (2010). Em todos estes trabalhos, uma posição unânime refere-se à importância de fatores relacionados ao mercado de trabalho, como empregos e salários, para a redução da desigualdade de renda.

Os dados apresentados por Soares (2006) mostram que a participação da renda do trabalho na renda total esteve sempre próxima de 80\%, entre 1995 e 2004. Trata-se de uma participação considerável e que gera uma expectativa de que este componente tenha uma contribuição significativa para a queda da desigualdade de renda ocorrida recentemente. Já Hoffmann (2006) atribui à renda do trabalho uma contribuição superior a 68\% para explicar a redução do índice de Gini entre 2001 e 2004. Considerando um período maior, 1995 a 2004, Soares (2006) e Soares et al. (2006) encontram contribuições ainda maiores desse componente da renda, de $73 \%$ e $85 \%$ da queda observada no índice de Gini entre 1995 e 2004. Já Barros et al. (2010) atribui que $60 \%$ da redução da desigualdade de renda entre 2001 e 2007, também mensurada pelo índice de Gini, deve-se a melhorias na distribuição dos rendimentos derivados do trabalho.

Considerando-se então os resultados relatados na literatura, a desigualdade de rendimentos do trabalho e os seus determinantes possuem um papel fundamental para a dinâmica da desigualdade da renda brasileira. Dessa forma, sua análise permitirá aprofundar o conhecimento sobre o fenômeno, além de ajudar a compreender como políticas públicas podem tornar a redução da desigualdade de renda no Brasil um processo sustentável.

Com efeito, considerando-se o problema em uma perspectiva microeconométrica, cujo cerne está na decomposição de medidas de desigualdade de rendimentos e na mudança observada dessas medidas ao longo do tempo, o presente estudo aplicou a abordagem de decomposição baseada em regressões, adotando os métodos propostos por Fields (2003) e Yun (2006). Com o propósito de avaliar mudanças na desigualdade de salários no Brasil entre 1995 e 2014,

2 Que incluem além dos rendimentos, fatores demográficos e relacionados com a oferta de trabalho. 
realizou-se o exercício de decomposição em dois subperíodos: 19952004 e 2004-2014. ${ }^{3}$ Dentre as variáveis explicativas no modelo de salários foram considerados fatores relacionados a três aspectos: capital humano, discriminação e segmentação. Fatores relacionados a estes aspectos são levantados pela literatura como os principais determinantes das disparidades de rendimentos no mercado de trabalho.

A principal contribuição do artigo está nos resultados obtidos com a aplicação do método proposto por Yun (2006) à análise de mudanças na desigualdade salarial brasileira. De forma relativamente simples perante às outras alternativas, o método possibilita a decomposição detalhada de mudança na desigualdade salarial, com a identificação dos chamados efeito preço e efeito quantidade para cada fator explicativo na equação de rendimentos. A análise desses efeitos proporciona considerações interessantes e pouco exploradas na literatura brasileira. ${ }^{4}$ Dentre os resultados obtidos, destaca-se a contribuição das mudanças educacionais para a recente queda da desigualdade salarial no Brasil. Essa contribuição que pode ser atribuída essencialmente à queda dos retornos educacionais (efeito preço), uma vez que o aumento da escolaridade dos trabalhadores (efeito quantidade) apresentou um efeito pouco expressivo entre 1995 e 2004, e até mesmo contrário à maior equidade de salários entre 2004 e 2014. Fatores relacionados à discriminação e segmentação também apresentaram contribuições significantes, mas em magnitudes relativamente modestas.

Além dessa introdução, o presente artigo se divide em outras cinco seções. Na próxima seção é feita uma revisão da literatura nacional com o objetivo de reunir informações sobre os principais determinantes da desigualdade de rendimentos do trabalho no Brasil. O método de decomposição empregado na análise é o tema da terceira seção, onde são revisadas as principais referências para a metodologia adotada. Em seguida são apresentados os comentários sobre a base de dados e os resultados da estimação das equações de salários. A análise e discussão dos resultados da decomposição são reportados

3 O período sob consideração se inicia após o Plano Real até o último ano com dados disponíveis no momento de realização da pesquisa. Uma breve análise da trajetória dos salários reais médios entre 1995 e 2014, com base nos dados da PNAD/IBGE mostra um comportamento diferenciado entre estes dois subperíodos; onde se observa uma redução no primeiro (1995-2004) e um forte aumento no segundo (2004-2014).

4 Exercícios de decomposição semelhantes foram realizados por Barros et al. (2007c), Foguel e Azevedo (2007) e Menezes-Filho et al. (2006 e 2007) aplicando métodos diferentes de decomposição. 
na quinta seção. Por fim, são apresentadas as considerações finais do presente estudo, resumindo os principais resultados obtidos.

\section{Revisão de literatura}

Barros e Mendonça (1995) desenvolvem um arcabouço teórico em que dois tipos de desigualdades podem ser identificados no mercado de trabalho: desigualdade de condições e desigualdade de resultados. A desigualdade de condições ocorre ainda antes de os indivíduos ingressarem nesse mercado, em etapas de acumulação de capital humano. Nessa fase os indivíduos procuram utilizar-se de suas habilidades inatas, recursos públicos e privados para acumular determinados níveis de capital humano e posteriormente obter bons resultados em termos de salários. Já a desigualdade de resultados (em que podemos entender a desigualdade salarial) reflete as diferenças individuais em termos de capital humano acumulado, corroborando com a desigualdade de condições e a teoria do capital humano, e as diferenças não relacionadas aos atributos produtivos de cada trabalhador, mas associadas à segmentação do mercado de trabalho e à discriminação.

Ainda de acordo com esses autores, as disparidades nos rendimentos do trabalho podem ser explicadas por diferenças de produtividade, e também pelos efeitos da discriminação ou da segmentação. A primeira explicação é natural, uma vez que é de se esperar que trabalhadores mais produtivos, de acordo com suas dotações de capital humano ou habilidades intrínsecas, recebam melhores remunerações. Nesse caso, o mercado de trabalho estaria apenas reproduzindo ou revelando desigualdades preexistentes. Essa ideia é amparada na teoria do capital humano, em que a reprodução da desigualdade no mercado de trabalho ocorre por que os trabalhadores são diferentes em termos de qualidade. Assim, a desigualdade de renda depende da distribuição de atributos produtivos entre os trabalhadores e também da forma como o mercado de trabalho remunera diferentes qualidades.

A segunda explicação se deve a deficiências do mercado, quando remunerações diferenciadas são atribuídas a trabalhadores igualmente produtivos. Os casos clássicos desse tipo de desigualdade são os provenientes de discriminação por gênero e raça, em que diferen- 
ciais de rendimentos são observados em favor de indivíduos do sexo masculino e de cor branca. A segmentação do mercado de trabalho, como a existente entre regiões e setores da economia, também é capaz de gerar diferenciais de rendimentos de natureza semelhante. Considerando-se estes aspectos, o mercado de trabalho estaria cumprindo um papel de produtor de desigualdades.

Se todos os trabalhadores e postos de trabalhos fossem homogêneos, o mercado se preocuparia apenas em definir o valor dos salários pagos, que seriam iguais para todos aqueles igualmente produtivos, não havendo motivos para que se remunerem pessoas em iguais condições de maneira distinta. No entanto, a realidade mostra que trabalhadores com atributos produtivos semelhantes recebem remunerações diferentes, o que configura criação de desigualdade por parte do mercado de trabalho. Nesse mesmo sentido, Ramos e Vieira (2001) apontam que os diferenciais de salários existem como consequência de compensações por fatores não pecuniários, heterogeneidade dos trabalhadores, segmentação e discriminação. Para esses autores, no caso dos dois primeiros elementos, o mercado de trabalho se apresentaria como revelador de desigualdades, pois as diferenças de remuneração surgiram em função das diferenças de qualidade de postos de trabalho e da produtividade dos trabalhadores. Nos dois casos restantes, o mercado se revelaria como gerador de desigualdades, na medida em que os rendimentos passariam a não refletir corretamente a produtividade marginal do fator trabalho.

Barros et al. (2007b) mostram evidências de que fatores como discriminação e segmentação, que a princípio não afetam a produtividade, explicam grandes parcelas da desigualdade de rendimentos no mercado de trabalho. Os autores avaliam como a discriminação por gênero e por raça, e a segmentação por regiões, por setores e por formalização do emprego, contribuíram para a redução do grau de desigualdade dos rendimentos do trabalho entre 2001 e 2005. Eles concluem que, com exceção da segmentação formal-informal, os efeitos discriminatórios e dos diferenciais regionais e setoriais diminuíram, contribuindo para a redução das disparidades de rendimentos.

Barros et al. (2007c) ainda avaliam a relação entre a distribuição de rendimentos do trabalho e as mudanças na composição educacional na primeira metade da década de 2000. Para os autores, essa relação ocorre por duas vias. Na primeira delas, a distribuição de rendimen- 
tos depende da distribuição de escolaridade. Na medida em que a remuneração é uma função crescente do nível educacional, quanto maior for a desigualdade educacional, maior será a desigualdade de rendimentos. A segunda via depende da forma como cada nível de escolaridade (ou ano de estudo) é valorado pelo mercado de trabalho, ou seja, depende dos retornos à educação. Dado um grau de desigualdade educacional, quanto maior for a sensibilidade das remunerações a mudanças na escolaridade (sensibilidade medida pelo retorno educacional), maior será a desigualdade de rendimentos.

Também com o foco de investigar a contribuição das mudanças educacionais, Meneses-Filho et al. (2006 e 2007) analisam o comportamento da desigualdade de rendimentos dos homens no Brasil entre 1977 e 2004,,$^{5}$ empregando regressões quantílicas e simulações contrafactuais para decompor mudanças na variância do logaritmo dos salários em termos dos efeitos preço e composição. Os principais resultados obtidos mostram que o efeito preço apresentou uma contribuição favorável na direção de menor desigualdade ao longo de toda a década de 1990, tornando mais significativa ao final da década e no início dos anos 2000. Já o efeito composição apresentou uma contribuição na direção oposta. Para os autores, ambos os efeitos se compensaram, permitindo uma relativa estabilidade da desigualdade de rendimentos entre grupos educacionais até o final da década de 1990, quando passaram a ter impactos na mesma direção de redução da desigualdade.

Foguel e Azevedo (2007) empregam uma versão modificada do método de decomposição de Juhn, Murphy e Pierce (1993) para estudar variações em medidas de desigualdade (coeficiente de Gini, índice de Theil-L, e razões 90/10 e 80/20) no Brasil entre 1995 e 2005. O trabalho avalia os efeitos preço e composição (quantidade), além de um componente residual atribuído a não observáveis. Avaliando dois subperíodos, 1995-2001 e 2001-2005, eles observaram que os efeitos quantidade e residual foram os mais importantes para explicar as mudanças no primeiro caso. No segundo subperíodo, o efeito preço, que antes se mostrou pouco significante, passa a ter maior relevância para explicar a queda na desigualdade de rendimentos do trabalho. Dentre estes resultados, novamente a

Meneses-Filho, Fernandes e Picchetti (2006), para o período 1977-2007, e Meneses-Filho, Fernandes e Picchetti (2007), para o período 1981-2004. 
contribuição das mudanças educacionais mais significativas ocorrem em função da redução dos retornos à educação.

Dentre os estudos mais recentes, Cunha e Vasconcelos (2012) verificam que a heterogeneidade educacional no mercado de trabalho brasileiro é o seu principal determinante e está entre os fatores que mais contribuíram para sua queda no período recente. Os autores também apontam para uma ampliação dos diferenciais relativos à segmentação formal-informal ao longo da década de 2000.

\section{Método de decomposição}

Decomposições de mudanças na desigualdade já constituem um arcabouço bem estabelecido na literatura econômica, sendo o método mais tradicional baseado na decomposição de mudanças em medidas de desigualdade por subgrupos populacionais. Bourguignon (1979) define que uma medida de desigualdade para ser decomposta deve possui propriedades que permitem que a desigualdade total possa ser expressa em termos da média ponderada da desigualdade dentro de subgrupos populacionais e da desigualdade entre estes subgrupos.

Outra abordagem apresentada nos trabalhos de Pyatt, Chen, e Fei (1980) e Shorrocks (1982) mostra a decomposição da desigualdade em fatores componentes da renda, na qual se emprega o conceito de coeficiente de concentração para decompor o Índice de Gini segundo as diferentes fontes de rendimentos que compõem a renda total, tais como os rendimentos do trabalho, rendimentos de capital e transferências. Esse método de decomposição foi empregado em diversos estudos sobre a distribuição de renda no Brasil tais como Soares (2006), Soares et al. (2006), Hoffmann (2006) e Hoffman e Oliveira (2014).

A partir dos trabalhos seminais de Oaxaca (1973) e Blinder (1973), o termo decomposição passou a designar a decomposição de diferença salariais entre grupos definidos de acordo com características individuais, inicialmente de acordo com gênero e raça. $\mathrm{O}$ método de decomposição de Oaxaca-Blinder, que tem como base as equações de 
rendimentos mincerianas, ${ }^{6}$ tornou-se um método padrão em diversas abordagens aplicadas em economia do trabalho em função de sua simplicidade e poder analítico.

Ao longo das últimas décadas, o método de Oaxaca-Blinder evoluiu e serviu de inspiração para o desenvolvimento de outras metodologias de decomposição. Os principais desenvolvimentos analíticos voltados para o estudo da desigualdade de rendimentos do trabalho ocorreram nas décadas de 1980 e 1990. O aumento da desigualdade salarial observado nos Estados Unidos após a década de 1970 motivou a evolução dos métodos de decomposição, que desde então incorporaram formas de avaliar mudanças na distribuição de renda. Nesse cenário, o método tradicional de decompor diferenciais de rendimentos médios deixou de ser suficiente e o foco se voltou para a análise de mudanças na distribuição dos rendimentos. Os trabalhos de Juhn, Murphy e Pierce - JMP (1993) e DiNardo, Fortin e Lemieux - DFL (1996) são as principais referências nesse contexto.

O método de decomposição de JMP (1993) permite a análise de mudanças na desigualdade de rendimentos entre dois períodos do tempo em termos de três componentes: uma parte explicada por diferenças nas características observáveis (efeito quantidade), uma parte explicada por diferenças nos coeficientes (efeito preço) e uma parte atribuída a fatores não observados (efeito residual). Apesar de terem observado ganhos reais nos salários médios dos trabalhadores norte-americanos entre 1963 e 1989, os autores chamam a atenção para o aumento na desigualdade de rendimentos do trabalho nos Estados Unidos ao longo dos anos de 1970 e 1980. Ao aplicar a decomposição proposta para diferentes medidas de desigualdade, eles concluíram que a explicação para o aumento da desigualdade de rendimentos não está na distribuição de qualificação entre os trabalhadores, mas no aumento do retorno sobre a qualificação, resultante de uma maior demanda por trabalho qualificado.

Por sua vez, DFL (1996) propõem um método semiparamétrico baseado em funções de densidade do tipo kernel. O objetivo dos autores era avaliar os efeitos da sindicalização e de choques de demanda e oferta sobre diferentes indicadores de desigualdade, calculados para o mercado de trabalho americano nas décadas de 1970, 1980 e início dos anos de 1990. Dentre as conclusões obtidas, os autores

6 Mincer, J. Schooling, Experience and Earnings. Columbia University Press: New York, 1974. 
mostraram que a sindicalização e o valor real do piso salarial possuem grandes contribuições para as mudanças observadas na desigualdade de salários.

Já no início dos anos de 2000, novos desenvolvimentos surgiram como os métodos baseados em modelos de regressão. ${ }^{7}$ Dentre eles, Fields (2003) adota o aparato das equações de rendimentos estimados por Mínimos Quadrados Ordinários e o desenvolvimento axiomático apresentado em Shorrocks (1982). O método de Fields permite estimar a contribuição individual de cada variável explicativa na equação de salários para a desigualdade de rendimentos observada em um dado grupo ou período de tempo, e para diferenças na desigualdade de rendimentos entre dois grupos ou períodos. Ao aplicar o método proposto na análise da desigualdade de rendimentos nos Estados Unidos entre 1979 e 1999, Fields (2003) concluiu que dentre as variáveis de gênero, raça, ocupação, indústria e região, a escolaridade foi o principal fator para a explicação da desigualdade de rendimentos em cada ano considerado na amostra e para o aumento na desigualdade ao longo do período avaliado.

Com o objetivo de estudar as mudanças na desigualdade de rendimentos do trabalho nos Estados Unidos entre 1969 e 1999, Yun (2006) propôs uma síntese dos métodos de JMP (1993) e Fields (2003). O método de JMP (1993) permite a decomposição de medidas de desigualdade em termos dos três componentes já citados, mas não permite avaliar a contribuição de diferentes características individuais. Por sua vez, o método apresentado por Fields (2003), com base em modelos de regressão, permite a realização de uma decomposição detalhada. Dessa forma, a síntese de Yun (2006) é um método de decomposição que, aplicado à medida de log-variância dos rendimentos, permite a estimação dos chamados efeito preço e efeito quantidade para cada variável explicativa de uma equação de rendimentos, além do efeito residual.

Dentre os fatores considerados por Yun (2006), a educação foi o que melhor explicou a elevação da desigualdade, com predominância do efeito preço desse atributo, principalmente na decomposição da desigualdade entre as mulheres. No entanto, ele conclui que os efeitos preço e quantidade agregados praticamente se anularam no período

7 Além do método proposto por Fields (2003), pode-se citar os trabalhos de Bourguignon et al. (2001) e Morduch e Sicular (2002). 
analisado e identifica um elevado grau de explicação do componente residual.

Os métodos empregados nos artigos citados acima possuem como base equações de rendimentos, estimados pelo método de Mínimos Quadrados Ordinários (MQO), com a seguinte especificação:

$$
y_{i t}=\beta_{0 t}+\sum_{k=1}^{K} \beta_{k t} x_{i k t}+e_{i t}
$$

Nessa equação, para cada indivíduo indexado por $i$, o termo $y_{i t}$ denota rendimentos do trabalho/salários (em logaritmo) e é explicado por $K$ características dos trabalhadores e dos postos de trabalho por eles ocupados, representadas pelas quantidades $x_{i k t}$, e pelo termo de erro da regressão, $e_{i t}$. $\mathrm{O}$ índice $t$ denota dois períodos, aqui definidos simplesmente por $\mathrm{A}$ e $\mathrm{B}$, mas se deve deixar claro que não se trata necessariamente de uma estrutura de dados em painel. A partir dos rendimentos estimados em cada equação, uma medida de desigualdade pode ser obtida para cada período $t=A, B$ da seguinte forma:

$$
\begin{aligned}
& I_{A}=I_{A}\left(y_{1 A}, y_{2 A}, \cdots, y_{M A}\right) \\
& I_{B}=I_{1}\left(y_{1 B}, y_{2 B}, \cdots, y_{N B}\right)
\end{aligned}
$$

Em que $y_{i t}$ representa o rendimento do trabalhador $i$ no período $t$, com $i=1 \cdots M$ se $t=A$ e $i=1 \cdots N$ se $t=B$. As próximas subseções apresentam os métodos de decomposição abordados.

\subsection{O método JMP (1993)}

Como apresentado anteriormente, o método JMP (1993) permite a decomposição de mudanças de diferentes estatísticas de uma distribuição de rendimentos em três componentes: efeito quantidade, efeito preço e efeito de não observáveis (ou residual); tendo como base equações de rendimentos estimadas por MQO.

O primeiro desses componentes refere-se ao efeito de uma mudança nas características observáveis dos trabalhadores, as quais são representadas pelas variáveis explicativas da regressão. O segundo componente, denominado como efeito preço, relaciona-se às estimativas 
dos coeficientes associados a essas características. Dessa forma, o efeito preço tem como objetivo captar como mudanças nos retornos afetaram a distribuição dos rendimentos. Por sua vez, o terceiro componente corresponde ao efeito de mudanças no termo residual da equação, comumente associado às variáveis não observáveis.

Como apresentado por Yun (2006), o procedimento de decomposição de JMP pode ser aplicado inicialmente pela estimação de equações de rendimentos para os dois períodos sob consideração e, utilizando-se valores das variáveis explicativas, os coeficientes estimados e os resíduos das regressões, constroem-se equações auxiliares contrafactuais de forma sequencial.

Iniciando-se com a equação de rendimentos para o período $t=A$, substitui-se os coeficientes dessa equação pelos coeficientes da equação do período $B\left(\beta_{k B}\right)$, mantendo as características e resíduos de $A\left(x_{i k A}, e_{i A}\right)$. Assim, obtém-se:

$$
y_{i}^{*}=\beta_{0 B}+\sum_{k=1}^{K} \beta_{k B} x_{i k A}+e_{i A}
$$

A segunda equação auxiliar é obtida com a substituição dos coeficientes e características do período $B\left(\beta_{k B}, x_{i k B}\right)$ e mantendo os resíduos de $A\left(e_{i A}\right)$, obtém-se:

$$
y_{i}^{* *}=\beta_{0 B}+\sum_{k=1}^{K} \beta_{k B} x_{i k B}+e_{i A}
$$

Por fim, com a substituição dos resíduos, tem-se:

$$
y_{i}^{* * *}=y_{i B}=\beta_{0 B}+\sum_{k=1}^{K} \beta_{k B} x_{i k B}+e_{i B}
$$

Usando as equações estimadas de $y_{i A}, y_{i}^{*}, y_{i}^{* *}$ e $y_{i B}$, podem ser calculadas medidas de desigualdade correspondentes para cada equação de salários, obtendo $I_{y_{A}}, I_{y^{*}}, I_{y^{* *}}$ e $I_{y}$. Segundo Yun (2006), qualquer índice de desigualdade pode ser usado com o método JMP. 
A diferença na desigualdade de rendimentos entre os períodos $A$ e $B$ é decomposta da seguinte forma:

$$
I_{y_{A}}-I_{y_{B}}=\left[I_{y_{A}}-I_{y^{*}}\right]+\left[I_{y^{*}}-I_{y^{* *}}\right]+\left[I_{y^{* *}}-I_{y_{B}}\right]
$$

Nessa expressão pode-se identificar os componentes:

- Efeito preço (efeito da diferença nos coeficientes) $=\left[I_{y_{A}}-I_{y^{*}}\right]$;

- Efeito quantidade (efeito da diferença nas características) = $\left[I_{y^{*}}-I_{y^{* *}}\right]$

- Efeito residual (efeito da diferença na distribuição de não-observáveis) $=\left[I_{y^{* *}}-I_{y_{B}}\right]$.

\subsection{O método de Fields (2003)}

Com base na equação de rendimentos estimada, o método proposto por Fields (2003) contabiliza a contribuição de cada variável explicativa para o nível e para mudanças em um indicador de desigualdade. Assim, o método decompõe uma medida de desigualdade destacando as contribuições de cada atributo individual em um ponto no tempo (decomposição em nível) e, com base nesse resultado, compara a desigualdade entre dois períodos de tempo (decomposição da diferença).

A contribuição de cada variável $k$, é definida como uma "ponderação relativa" e indica o percentual de desigualdade de rendimentos que pode ser atribuída ao $k$-ésimo fator. Essa "ponderação relativa" é derivada a partir da decomposição da variância de $y$, dada por:

$$
\operatorname{var}(y)=\sum_{k=1}^{K} \operatorname{cov}\left(\beta_{k} x_{k}, y\right)+\operatorname{cov}(e, y)
$$

Em que $\operatorname{cov}(e, y)=\operatorname{var}(e)$, desde que se assume a hipótese de que $\operatorname{cov}\left(e, \beta_{k} x_{k}\right)=0$. Assim, a contribuição de cada fator $k$, denotada por $s_{k}$ é:

$$
s_{k}=\frac{\operatorname{cov}\left(\beta_{k} x_{k}, y\right)}{\operatorname{var}(y)}=\frac{\beta_{k} \cdot s d\left(x_{k}\right) \cdot \operatorname{corr}\left(x_{k}, y\right)}{s d(y)}
$$


Dessas expressões temos que:

$$
100 \%=\sum_{k=1}^{K} s_{k}+s_{e}
$$

Considerando apenas a parcela explicada do modelo $\left(\sum_{k=1}^{K} s_{k}=R^{2}\right)$, a contribuição de cada variável $k$, denotada por $p_{k}$, é:

$$
p_{k} \equiv \frac{s_{k}}{R^{2}}
$$

Fields (2003) argumenta que a contribuição relativa de cada fator para a desigualdade é invariante à escolha da medida de desigualdade sob os seis axiomas propostos por Shorrocks (1982). ${ }^{8}$ Portanto, a contribuição de uma característica individual sobre a desigualdade de rendimentos é simplesmente $s_{k} \cdot I$. No caso dos resíduos, estes são tratados como os demais fatores, mas com coeficientes $\beta=1$.

$\mathrm{Na}$ decomposição da diferença, a parcela de contribuição do fator para a diferença na desigualdade entre dois períodos A e B é definida como:

$$
\Pi_{k}=\frac{\left(s_{k A} I_{A}-s_{k B} I_{B}\right)}{\left(I_{A}-I_{B}\right)}
$$

\subsection{Unificando os métodos de JMP e Fields - a síntese de Yun (2006)}

O método proposto por JMP (1993) permite a distinção dos efeitos preço e quantidade, mas a decomposição é realizada de forma

8 (1) Número de componentes. Uma medida de desigualdade deve ser dividada em $K$ componentes, denotados por $s_{k}\left(Y^{1}, \cdots, Y^{K} ; K\right)$, um para cada fator da renda. (2) Continuidade e simetria. Cada $s_{K}$ é contínuo em $Y^{k}$ e é tratado de forma simétrica, tal que, $s_{K}\left(Y^{1}, \cdots, Y^{K} ; K\right)=s_{\Pi_{k}}\left(Y^{\Pi_{1}}, \cdots, Y^{\Pi_{K}} ; K\right)$, para qualquer permutação $\Pi_{k}, \cdots \Pi_{k}$ de $1, \cdots, K$. (3) Independência do nível de desagregação. A contribuição de cada fator para a desigualdade independe da forma em que os demais fatores são agrupados. (4) Consistência da decomposição. A soma da contribuição dos resultados na medida de desigualdade, ou seja, $\sum_{k} s_{k}\left(Y^{1}, \cdots, Y^{K} ; K\right)=I(Y)$. (5) a) Simetria populacional. Considerando uma matriz de permutação $n \times n$ denotada por $P, s\left(Y^{k} P, Y P\right)=s\left(Y^{k}, Y\right)$, ou seja, os indivíduos são tratados simetricamente; b) Normalização para a igualdade na distribuição dos fatores. Considerando que todos os recipientes de renda (indivíduos ou famílias) possuam o mesmo valor para o fator $k$, e a média de $Y_{k}$, dada por $\mu_{k}$, então a contribuição desse fator para a medida de desigualdade é $s_{k}\left(\mu_{k}, Y\right)=0$ para todo $\mu_{k}$. (6) Simetria dual dos fatores. Supondo que a distribuição de um fator seja uma simples permutação de outro, ambos possuem a mesma contribuição para a medida de desigualdade. Assim para toda permutação $P, s\left(Y^{k}, Y^{k}+Y^{k} P\right)=s\left(Y^{k} P, Y^{k}+Y^{k} P\right)$. 
agregada. Já o método proposto por Fields (2003) permite uma decomposição desagregada, fornecendo as contribuições de fatores individuais para as diferenças na desigualdade de rendimentos, mas sem se decompor em efeitos preço e quantidade. Yun (2006) faz uma síntese dos métodos de JMP e Fields, unificando os procedimentos de decomposição com base nas equações de rendimentos.

Considerando a variância do logaritmo dos rendimentos como medida de desigualdade, Yun (2006) propõe a decomposição realizada na seguinte expressão:

$$
\begin{aligned}
& \operatorname{var}\left(y_{A}\right)-\operatorname{var}\left(y_{B}\right)=\left[\operatorname{var}\left(y_{A}\right)-\operatorname{var}\left(y_{i}^{*}\right)\right]+\left[\operatorname{var}\left(y_{i}^{*}\right)-\operatorname{var}\left(y_{B}\right)\right] \\
& =\sum_{k=1}^{K}\left[s_{k A} \cdot \operatorname{var}\left(y_{A}\right)-s_{k *} \cdot \operatorname{var}\left(y_{i}^{*}\right)\right]+\sum_{k=1}^{K}\left[s_{k *} \cdot \operatorname{var}\left(y_{i}^{*}\right)-s_{k B} \cdot \operatorname{var}\left(y_{B}\right)\right] \\
& +\left[\operatorname{var}\left(e_{A}\right)-\operatorname{var}\left(e_{B}\right)\right]
\end{aligned}
$$

Nessa expressão, a primeira parte deriva do método de JMP e a segunda da metodologia apresentada por Fields. O primeiro somatório representa a parcela da mudança na desigualdade salarial que pode ser atribuída às variações nos coeficientes da regressão (efeito preço); no segundo somatório tem-se a contribuição das mudanças na composição das características individuais (efeito quantidade) e, por fim, o termo residual. ${ }^{9}$

\section{Base de dados e equações mincerianas}

No presente estudo são utilizados dados brasileiros de 1995 a 2014, provenientes da Pesquisa Nacional por Amostra de Domicílios (PNAD) levada a campo pelo Instituto Brasileiro de Geografia e Estatística (IBGE). Foram obtidas subamostras, uma para cada ano considerado, aplicando alguns filtros coerentes com os objetivos do trabalho e as ponderações amostrais fornecidas pelo IBGE. São considerados apenas indivíduos com informações disponíveis para todas as variáveis investigadas, compreendendo os ocupados com idade entre 18 e 65 anos e residentes em áreas urbanas. Com a proposta de

9 Assim como em qualquer modelo de regressão, o termo de resíduo incorpora variáveis não observáveis, variáveis omitidas e afins. No contexto da decomposição, seu efeito é interpretado como a diferença de não observáveis e respectivos retornos. 
avaliar mudanças na desigualdade de salários, a variável explicada pelo modelo de regressão corresponde ao salário/hora (em logaritmo) obtido pelo trabalho principal dos indivíduos ocupados que declararam uma carga horária entre 20 e 72 horas nessa ocupação.

Com relação às variáveis explicativas, vale ressaltar que estas foram baseadas nas três principais fontes de desigualdade descritas pela literatura comentada na segunda seção: heterogeneidade de capital humano, discriminação e segmentação. De modo geral, as variáveis empregadas são muito semelhantes às utilizadas na análise realizada por Fields (2003) e Yun (2006). No Quadro 1 encontra-se a descrição precisa das variáveis utilizadas no modelo de salários.

Quadro 1 - Descrição das variáveis explicativas utilizadas na estimação das equações de rendimentos.

\begin{tabular}{|c|c|}
\hline Variável & Descrição da variável \\
\hline \multicolumn{2}{|r|}{ Capital Humano } \\
\hline Educação & $\begin{array}{l}\text { Foi empregado um conjunto de dummies discriminando a escolaridade dos indivíduos em } 5 \\
\text { categorias: analfabetos ou com o } 1^{\circ} \text { ciclo do fundamental incompleto (até } 3 \text { anos de estudo); } \\
1^{\circ} \text { ciclo do fundamental completo (de } 4 \text { a } 7 \text { anos de estudo); } 2^{\circ} \text { ciclo do ensino fundamental } \\
\text { completo (de } 8 \text { a } 10 \text { anos de estudo); ensino médio completo (de } 11 \text { a } 14 \text { anos de estudo); e } \\
\text { algum ensino superior (acima de } 15 \text { anos de estudo). }\end{array}$ \\
\hline Experiência & $\begin{array}{l}\text { A variável experiência foi obtida subtraindo da idade do indivíduo a idade que ele começou } \\
\text { a trabalhar, reportada na pesquisa da PNAD. Também foi empregada na forma quadrática. }\end{array}$ \\
\hline Permanência & $\begin{array}{l}\text { A variável permanência considera o período em que o indivíduo está empregado no mesmo } \\
\text { trabalho. Da mesma forma que a variável experiência, um termo quadrático é testado. }\end{array}$ \\
\hline \multicolumn{2}{|r|}{ Características de gênero e raça } \\
\hline Gênero & $\begin{array}{l}\text { A variável mulher é uma dummy que considera o gênero da pessoa com valor nulo para pes- } \\
\text { soas do sexo masculino e um para o sexo feminino. }\end{array}$ \\
\hline Cor/raça & $\begin{array}{l}\text { A variável branco é uma dummy que considera a cor/raça da pessoa com valor um para indi- } \\
\text { víduos que se declararam brancos e zero para negros e pardos. }\end{array}$ \\
\hline \multicolumn{2}{|r|}{ Segmentação do mercado de trabalho } \\
\hline Setor & $\begin{array}{l}\text { O setor de atividade é captado por diversas dummies: agrícola (categoria base), indústria, } \\
\text { serviços (incluindo comércio e administração pública). }\end{array}$ \\
\hline Ocupação & $\begin{array}{l}\text { A posição de ocupação é captada por uma dummy referente ao tipo de vínculo de trabalho, } \\
\text { assumindo valor zero se formal (com carteira ou funcionário público) e um se informal (sem } \\
\text { carteira de trabalho assinada). }\end{array}$ \\
\hline Região & $\begin{array}{l}\text { Um conjunto de variáveis dummies para captar a existência de segmentação regional no mer- } \\
\text { cado de trabalho: Norte, Nordeste (categoria base), Sudeste, Sul e Centro-Oeste. E uma va- } \\
\text { riável binária metropolitano que assinala com valor um para indivíduos residentes na região } \\
\text { metropolitana e zero em caso contrário. }\end{array}$ \\
\hline
\end{tabular}

Fonte: Elaboração própria. 
A Tabela 1 a seguir apresenta estatísticas descritivas para as subamostras referentes aos anos de 1995, 2004 e 2014. Note que existem algumas evidências importantes das transformações ocorridas no mercado de trabalho urbano ao longo do período considerado.

Tabela 1 - Estatísticas descritivas da amostra (1995, 2004 e 2014).

\begin{tabular}{|c|c|c|c|c|c|c|}
\hline \multirow{2}{*}{ Variáveis Explicativas } & \multicolumn{2}{|r|}{1995} & \multicolumn{2}{|r|}{2004} & \multicolumn{2}{|r|}{2014} \\
\hline & Média & Desvio-Padrão & Média & Desvio-Padrão & Média & Desvio-Padrão \\
\hline \multicolumn{7}{|l|}{ Capital Humano } \\
\hline Educação (0-3 anos) & 21,1 & 0,4079 & 13,3 & 0,3400 & 7,7 & 0,2662 \\
\hline Educação (4-7 anos) & 32,4 & 0,4679 & 23,5 & 0,4243 & 16,1 & 0,3676 \\
\hline Educação (8-10 anos) & 16,8 & 0,3740 & 18,2 & 0,3856 & 16,8 & 0,3736 \\
\hline Educação (11-14 anos) & 21,6 & 0,4118 & 35,1 & 0,4773 & 43,9 & 0,4963 \\
\hline Educação (15 anos ou +) & 8,1 & 0,2726 & 9,8 & 0,2979 & 15,5 & 0,3622 \\
\hline Experiência & 19,6 & 12,1914 & 19,7 & 12,3010 & 20,9 & 12,9593 \\
\hline Experiência ^2 & 534,5 & 590,5429 & 541,3 & 579,4282 & 606,1 & 626,6732 \\
\hline Permanência & 5,2 & 6,6269 & 5,5 & 6,9760 & 5,9 & 7,6612 \\
\hline Permanência ^2 & 71,5 & 166,2812 & 79,3 & 178,4639 & 94,0 & 216,2309 \\
\hline \multicolumn{7}{|l|}{ Discriminação } \\
\hline Mulher & 41,8 & 0,4932 & 45,2 & 0,4977 & 46,3 & 0,4986 \\
\hline Branco & 58,1 & 0,4934 & 54,7 & 0,4978 & 46,8 & 0,4990 \\
\hline \multicolumn{7}{|l|}{ Segmentação } \\
\hline Agrícola & 5,2 & 0,2216 & 4,9 & 0,2158 & 3,2 & 0,1758 \\
\hline Indústria & 27,9 & 0,4485 & 27,3 & 0,4457 & 26,5 & 0,4412 \\
\hline Serviços & 66,9 & 0,4705 & 67,8 & 0,4674 & 70,3 & 0,4568 \\
\hline Formal & 70,6 & 0,4555 & 67,4 & 0,4686 & 75,9 & 0,4275 \\
\hline Informal & 29,4 & 0,4555 & 32,6 & 0,4686 & 24,1 & 0,4275 \\
\hline Metropolitano & 41,1 & 0,4920 & 35,5 & 0,4785 & 35,2 & 0,4777 \\
\hline Norte & 4,6 & 0,2092 & 6,1 & 0,2397 & 6,7 & 0,2506 \\
\hline Nordeste & 19,0 & 0,3925 & 20,0 & 0,3998 & 21,0 & 0,4076 \\
\hline Sudeste & 53,1 & 0,4990 & 49,8 & 0,5000 & 47,2 & 0,4992 \\
\hline Sul & 16,0 & 0,3671 & 16,3 & 0,3694 & 16,4 & 0,3700 \\
\hline Centro-Oeste & 7,2 & 0,2589 & 7,8 & 0,2688 & 8,7 & 0,2815 \\
\hline
\end{tabular}

Fonte: Elaboração Própria. Microdados PNAD/IBGE (1995, 2004 e 2014). 
Em 1995, mais de 50\% da força de trabalho não tinha sequer completado o ensino fundamental (até 7 anos de estudo), 17\% tinham completado apenas o ensino fundamental, $21,6 \%$ tinham completado o ensino médio e apenas $8 \%$ tinham estudado no ensino superior. Em 2014 , o grupo de menor escolaridade correspondia a menos de $25 \%$, mais de $40 \%$ já haviam concluído o ensino médio e aproximadamente $15 \%$ tinham estudado no ensino superior. As demais variáveis de capital humano, experiência e permanência não sofreram grandes mudanças no período. Destaca-se ainda uma maior participação das mulheres no mercado de trabalho, e a maior declaração por parte da população de negros e pardos (não brancos) também é uma mudança que deve ser ressaltada.

No que diz respeito às características de segmentação do mercado, chama a atenção para a grande, e crescente, participação do setor de serviços (que inclui o comércio e a administração pública) e as mudanças no grau de formalização, que aumentou entre 1995 e 2014. Já com relação à composição regional, o maior destaque está na redução da participação das áreas metropolitanas.

As equações de rendimentos necessárias para o procedimento de decomposição foram estimadas por $\mathrm{MQO}$, empregando a forma da Equação [1] para os anos de 1995, 2004 e 2014, e as variáveis especificadas no Quadro 1. A Tabela 2 apresenta os resultados dessas estimações. 
Tabela 2 - Resultado da Regressão de Salários: 1995, 2004 e 2014.

\begin{tabular}{|c|c|c|c|}
\hline Variáveis Explicativas & 1995 & 2004 & 2014 \\
\hline \multirow{2}{*}{ Educação (4-7 anos) } & $0,2076^{\star \star \star}$ & $0,1471^{* \star \star}$ & $0,1000^{\star \star \star}$ \\
\hline & $(-0,0068)$ & $(-0,0067)$ & $(-0,0076)$ \\
\hline \multirow{2}{*}{ Educação (8-10 anos) } & $0,4422^{* * *}$ & $0,3006^{* * *}$ & $0,1883^{* * *}$ \\
\hline & $(-0,0082)$ & $(-0,0073)$ & $(-0,0078)$ \\
\hline \multirow{2}{*}{ Educação (11-14 anos) } & $0,8776^{\star \star \star}$ & $0,6439^{* \star *}$ & $0,4160^{* \star \star}$ \\
\hline & $(-0,0080)$ & $(-0,0069)$ & $(-0,0073)$ \\
\hline \multirow{2}{*}{ Educação (15 anos ou +) } & $1,6735^{\star \star *}$ & $1,5303^{\star \star *}$ & $1,1767^{\star \star \star}$ \\
\hline & $(-0,0105)$ & $(-0,0087)$ & $(-0,0082)$ \\
\hline \multirow{2}{*}{ Experiência } & $0,0288^{* * *}$ & $0,0254^{* \star *}$ & $0,0171^{* * \star}$ \\
\hline & $(-0,0007)$ & $(-0,0006)$ & $(-0,0005)$ \\
\hline \multirow{2}{*}{ Experiência $^{2}$} & $-0,0005^{\star \star *}$ & $-0,0004^{\star \star *}$ & $-0,0003^{\star \star *}$ \\
\hline & $(0,0000)$ & $(0,0000)$ & $(0,0000)$ \\
\hline \multirow{2}{*}{ Permanência } & $0,0337^{\star \star *}$ & $0,0311^{* * *}$ & $0,0230^{* \star \star}$ \\
\hline & $(-0,0009)$ & $(-0,0008)$ & $(-0,0007)$ \\
\hline \multirow{2}{*}{ Permanência² } & $-0,0006^{\star * *}$ & $-0,0005^{\star * \star}$ & $-0,0002^{\star * *}$ \\
\hline & $(0,0000)$ & $(0,0000)$ & $(0,0000)$ \\
\hline \multirow{2}{*}{ Mulher } & $-0,3532^{\star \star *}$ & $-0,2759^{\star \star *}$ & $-0,2414^{\star \star *}$ \\
\hline & $(-0,0050)$ & $(-0,0041)$ & $(-0,0037)$ \\
\hline \multirow{2}{*}{ Branco } & $0,1586^{\star \star *}$ & $0,1319^{\star \star \star}$ & $0,0936^{* \star \star}$ \\
\hline & $(-0,0051)$ & $(-0,0042)$ & $(-0,0037)$ \\
\hline \multirow{2}{*}{ Indústria } & $0,4112^{\star \star *}$ & $0,2569^{\star \star *}$ & $0,2229^{* \star *}$ \\
\hline & $(-0,0116)$ & $(-0,0097)$ & $(-0,0104)$ \\
\hline \multirow{2}{*}{ Serviços } & $0,2811^{\star \star \star}$ & $0,2010^{\star \star \star}$ & $0,1692^{* \star *}$ \\
\hline & $(-0,0113)$ & $(-0,0095)$ & $(-0,0102)$ \\
\hline \multirow{2}{*}{ Informal } & $-0,2245^{\star \star *}$ & $-0,2893^{\star * *}$ & $-0,1755^{\star * *}$ \\
\hline & $(-0,0056)$ & $(-0,0044)$ & $(-0,0042)$ \\
\hline \multirow{2}{*}{ Metropolitano } & $0,1998^{\star * *}$ & $0,1689^{* * *}$ & $0,1116^{* \star \star}$ \\
\hline & $(-0,0049)$ & $(-0,0041)$ & $(-0,0037)$ \\
\hline \multirow{2}{*}{ Norte } & $0,3100^{* \star *}$ & $0,2760^{\star \star *}$ & $0,1736^{* \star \star}$ \\
\hline & $(-0,0120)$ & $(-0,0087)$ & $(-0,0076)$ \\
\hline \multirow{2}{*}{ Sudeste } & $0,3802^{* * *}$ & $0,3045^{\star * *}$ & $0,2338^{* * \star}$ \\
\hline & $(-0,0066)$ & $(-0,0053)$ & $(-0,0047)$ \\
\hline \multirow{2}{*}{ Sul } & $0,3207^{\star \star \star}$ & $0,2778^{\star \star \star}$ & $0,2741^{* \star *}$ \\
\hline & $(-0,0084)$ & $(-0,0067)$ & $(-0,0060)$ \\
\hline \multirow{2}{*}{ Centro-Oeste } & $0,3361^{\star \star *}$ & $0,3510^{* \star *}$ & $0,3213^{* \star *}$ \\
\hline & $(-0,0101)$ & $(-0,0080)$ & $(-0,0069)$ \\
\hline \multirow{2}{*}{ Intercepto } & $0,1894^{* * *}$ & $0,3080^{* * *}$ & $1,0057^{\star \star \star}$ \\
\hline & $(-0,0140)$ & $(-0,0118)$ & $(-0,0124)$ \\
\hline № Obs. & 66.733 & 83.846 & 87.124 \\
\hline$R^{2}$ (ajustado) & 0,5645 & 0,5571 & 0,4768 \\
\hline $\mathrm{F}$ & $4.804,77$ & $5.857,05$ & $4.410,55$ \\
\hline
\end{tabular}

Fonte: Elaboração Própria. Microdados PNAD/IBGE (1995, 2004 e 2013).

Erros- padrão robustos (White) entre parênteses. Significância estatística: ${ }^{*} \mathrm{p}<0.05$, ${ }^{* *} \mathrm{p}<0.01$, *** $\mathrm{p}<0.001$.

Para as variáveis associadas à educação, os coeficientes estimados se mostraram crescentes em relação ao nível de escolaridade, evidenciando a convexidade dos retornos educacionais em que indivíduos 
mais educados recebem um retorno significativamente maior. No entanto, ao comparar os resultados entre os anos considerados, tem-se uma evidência de redução no retorno educacional ao longo do período. Também pode-se relatar uma redução nas diferenças de retornos entre níveis de escolaridade, com exceção do nível mais elevado (15 anos ou mais). Resultado semelhante foi observado por Hoffmann e Oliveira (2014), que avalia a tendência dos retornos educacionais para trabalhadores empregados nos setores agrícola e não agrícola no Brasil entre 1992 e 2012.

Também foram observados retornos positivos para as variáveis de experiência e permanência no mesmo emprego, e a relação côncava que estas possuem com o nível de salário/hora é confirmada. No caso das variáveis que captam diferenças salariais por gênero e raça/cor, tem-se uma confirmação do diferencial de rendimentos a favor de homens e brancos. Uma comparação simples dos resultados entre os anos analisados mostra uma redução desse diferencial. No que diz respeito às variáveis que captam aspectos de segmentação setorial no mercado de trabalho, como era de se esperar, trabalhadores nos setores de indústria e serviços (que inclui comércio e administração pública) possuem compensações salariais positivas em relação aos trabalhadores do setor agrícola. Contudo, esse diferencial também apresentou reduções ao longo do período considerado.

Considerando os coeficientes que captam o diferencial entre trabalhadores formais e informais, tem-se a confirmação de um diferencial de rendimentos a favor dos trabalhadores com carteira de trabalho assinada. Nota-se que entre 1995 e 2004 o diferencial se amplia, conforme alguns trabalhos da literatura já haviam concluído; e entre 2004 e 2014 o diferencial segue a tendência dos demais apresentando uma redução.

A segmentação espacial e regional do mercado de trabalho também é observada com relação aos diferenciais de rendimentos positivos para os trabalhadores residentes em regióes metropolitanas e nas demais regiões em detrimento ao Nordeste; embora da mesma forma como foi observado para outras variáveis, alguns destes diferenciais vêm reduzindo ao longo do tempo.

Tais resultados são importantes para o objetivo central desse trabalho. O conhecimento da estrutura salarial permite a avaliação de como tais características, de trabalhadores e postos de trabalho, 
afetam a formação de salários e irão auxiliar na análise de como, e em que medida, essas características contribuíram para a queda na desigualdade verificada recentemente.

\section{Resultados da decomposição}

Nesta seção apresentam-se os resultados da decomposição da desigualdade salarial com o emprego das metodologias apresentadas anteriormente. A partir das equações de rendimentos estimadas e que tiveram seus resultados apresentados na seção anterior, aplicamse os métodos de decomposição propostos por Fields (2003) e Yun (2006). O exercício de decomposição detalhada permite obter estimativas da contribuição de cada fator para a desigualdade observada e para a mudança no período.

Vale destacar que a evolução da desigualdade salarial no Brasil apresentou uma tendência consistente de redução entre os anos de 1995 e 2014. O Gráfico 1 apresenta duas das principais medidas de desigualdade, a variância do logaritmo dos salários e o índice de Gini, considerando-se os dados da amostra.

Gráfico 1- Evolução da Desigualdade de rendimentos do trabalho, medidas selecionadas - Brasil (1995-2014).

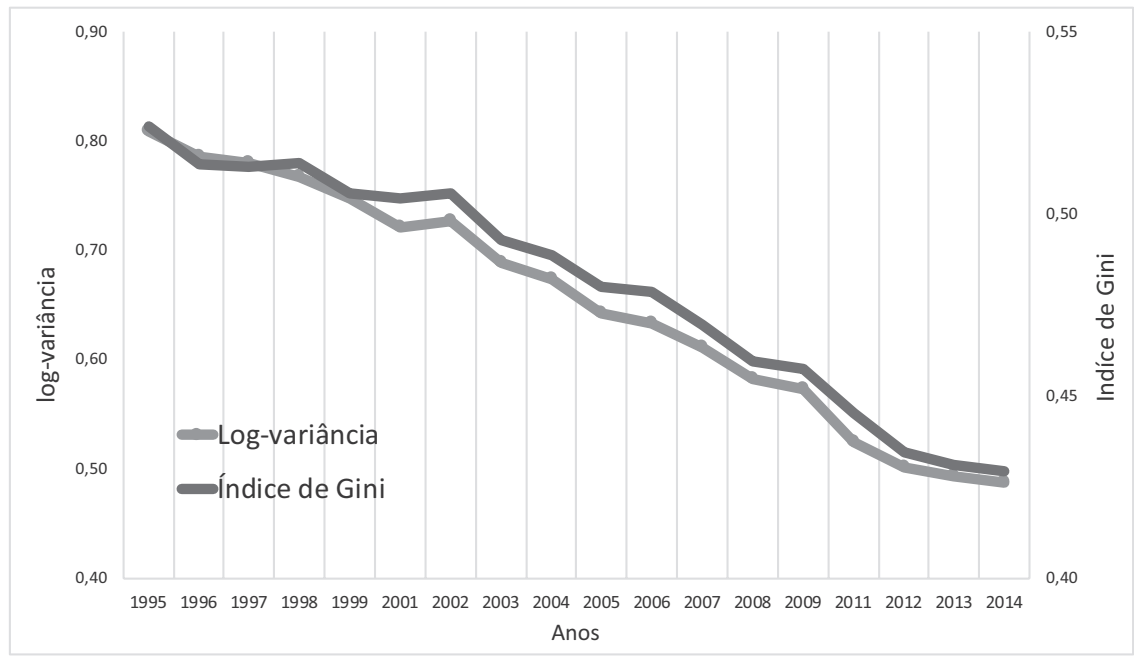

Fonte: Elaboração própria. Microdados PNAD/IBGE (1995-2014). 


\subsection{Decomposição do nível e da diferença - Fields (2003)}

Os resultados da aplicação direta do método de Fields (2003) são reportados nas Tabelas 3, 4 e 5. Com o objetivo de tornar a leitura desses resultados mais direta, os efeitos de características com duas ou mais categorias, como é o caso da escolaridade e de variáveis relacionadas ao setor de ocupação, tipo de ocupação e região, assim como variáveis de experiência (experiência e Experiência ${ }^{2}$ ) e permanência (permanência e Permanêcia ${ }^{2}$ ), foram agregados.

$\mathrm{Na}$ Tabela 3 tem-se o peso relativo de cada variável, $s_{k}$, calculado de acordo com a expressão [8], e a contribuição (percentual) de cada variável para a parte explicada, $p_{k}$, dada pela expressão [10].

Tabela 3 - Decomposição em nível - Ponderações relativas (em \%).

\begin{tabular}{lcccccc}
\hline \multirow{2}{*}{ Variáveis } & \multicolumn{2}{c}{1995} & \multicolumn{2}{c}{2004} & \multicolumn{2}{c}{2014} \\
\cline { 2 - 7 } & $s_{k}$ & $p_{k}$ & $s_{k}$ & $p_{k}$ & $s_{k}$ & $p_{k}$ \\
\hline Capital Humano & $\mathbf{3 8 , 8}$ & $\mathbf{6 8 , 7}$ & $\mathbf{3 9 , 5}$ & $\mathbf{7 0 , 9}$ & $\mathbf{3 7 , 0}$ & $\mathbf{7 7 , 6}$ \\
\hline Educação & 30,9 & 54,7 & 30,2 & 54,3 & 28,5 & 59,7 \\
Experiência & 2,6 & 4,6 & 3,1 & 5,6 & 2,2 & 4,6 \\
Permanência & 5,3 & 9,5 & 6,2 & 11,1 & 6,4 & 13,4 \\
\hline Discriminação & $\mathbf{5 , 3}$ & $\mathbf{9 , 4}$ & $\mathbf{3 , 7}$ & $\mathbf{6 , 7}$ & $\mathbf{3 , 1}$ & $\mathbf{6 , 5}$ \\
\hline Mulher & 3,0 & 5,3 & 1,8 & 3,2 & 1,7 & 3,5 \\
Branco & 2,4 & 4,2 & 1,9 & 3,5 & 1,4 & 3,0 \\
\hline Segmentação & $\mathbf{1 2 , 3}$ & $\mathbf{2 1 , 9}$ & $\mathbf{1 2 , 5}$ & $\mathbf{2 2 , 4}$ & $\mathbf{7 , 6}$ & $\mathbf{1 5 , 9}$ \\
\hline Setor & 2,0 & 3,6 & 1,0 & 1,9 & 0,5 & 1,1 \\
Ocupação & 4,2 & 7,5 & 6,4 & 11,4 & 2,9 & 6,0 \\
Região & 6,1 & 10,8 & 5,1 & 9,1 & 4,2 & 8,8 \\
\hline Resíduo & 43,5 & & 44,3 & & 52,3 & \\
$\mathbf{R}^{2}$ & 56,5 & & 55,7 & & 47,7 & \\
\hline
\end{tabular}

Fonte: Elaboração Própria. Microdados PNAD/IBGE (1995, 2004 e 2014).

Considerando a variância do logaritmo dos salários, a Tabela 4 apresenta as contribuições de cada variável para essa medida de desigualdade. 
Tabela 4 - Decomposição em nível - Contribuições para a variância dos salários $(\log )$.

\begin{tabular}{llll}
\hline & $\mathbf{1 9 9 5}$ & $\mathbf{2 0 0 4}$ & $\mathbf{2 0 1 4}$ \\
\hline Valor de Var. In(y) & $\mathbf{0 , 8 1}$ & $\mathbf{0 , 6 7}$ & $\mathbf{0 , 4 8}$ \\
\hline Capital Humano & $\mathbf{0 , 3 1}$ & $\mathbf{0 , 2 7}$ & $\mathbf{0 , 1 8}$ \\
\hline Educação & 0,25 & 0,20 & 0,14 \\
Experiência & 0,02 & 0,02 & 0,01 \\
Permanência & 0,04 & 0,04 & 0,03 \\
\hline Discriminação & $\mathbf{0 , 0 4}$ & $\mathbf{0 , 0 3}$ & $\mathbf{0 , 0 2}$ \\
\hline Mulher & 0,02 & 0,01 & 0,01 \\
Branco & 0,02 & 0,01 & 0,01 \\
\hline Segmentação & $\mathbf{0 , 1 0}$ & $\mathbf{0 , 0 8}$ & $\mathbf{0 , 0 4}$ \\
\hline Setor & 0,02 & 0,01 & 0,00 \\
Ocupação & 0,03 & 0,04 & 0,01 \\
Região & 0,05 & 0,03 & 0,02 \\
\hline Resíduo & 0,35 & 0,30 & 0,25 \\
\hline
\end{tabular}

Fonte: Elaboração Própria. Microdados PNAD/IBGE (1995, 2004 e 2014).

Na Tabela 5 são apresentados os resultados da aplicação da expressão [11], para a decomposição da diferença da variância do logaritmo dos salários. São avaliadas mudanças nos dois subperíodos 1995-2004 e 2004-2014.

Tabela 5 - Decomposição da diferença - Contribuições relativas para a mudança na desigualdade. Valores percentuais entre parênteses.

\begin{tabular}{lcc}
\hline & $1995-2004$ & $2004-2014$ \\
\hline \multirow{2}{*}{ Var. In(y) } & $-0,134$ & $-0,187$ \\
\hline Capital Humano & $(100)$ & $(100)$ \\
\hline \multirow{2}{*}{ Educação } & $-0,047$ & $-0,092$ \\
\multirow{2}{*}{ Experiência } & $(35,13)$ & $(49,29)$ \\
\hline \multirow{2}{*}{ Permanência } & $-0,046$ & $-0,065$ \\
Discriminação & $(34,08)$ & $(34,86)$ \\
& 0,000 & $-0,010$ \\
Mulher & $(-0,08)$ & $(5,48)$ \\
\multirow{2}{*}{ Branco } & $-0,002$ & $-0,011$ \\
& $(1,13)$ & $(5,66)$ \\
\hline \multirow{2}{*}{ Segmentação } & $-0,018$ & $-0,011$ \\
\hline \multirow{2}{*}{ Setor } & $(13,35)$ & $(6,00)$ \\
\hline \multirow{2}{*}{ Ocupação } & $-0,012$ & $-0,004$ \\
& $(8,89)$ & $(2,05)$ \\
Região & $-0,006$ & $-0,006$ \\
\hline Resíduo & $(4,46)$ & $(3,28)$ \\
\hline
\end{tabular}

Fonte: Elaboração Própria. Microdados PNAD/IBGE (1995, 2004 e 2014). 
Em primeiro lugar, as variáveis de capital humano (educação, experiência e permanência) explicaram aproximadamente $40 \%$ do nível de desigualdade, correspondendo a mais de $70 \%$ da parte explicada nos anos de 2004 e 2014. Em termos da diferença observada nos indicadores de desigualdade entre os períodos considerados, podese associar a estas variáveis a maior parcela de contribuição para a redução da desigualdade salarial. No subperíodo 1995-2004, as contribuições das variáveis de capital humano correspondiam a pouco mais de $35 \%$ da redução na medida de log-variância. No subperíodo 2004-2013, essa contribuição foi de quase 50\%.

Dentre as variáveis de capital humano, a contribuição da educação se apresentou como o principal determinante, tanto para a desigualdade em nível, quanto para a diferença. O efeito da escolaridade correspondeu a aproximadamente $30 \%$ do nível de desigualdade em 1995 e 2004, sendo um pouco mais baixo em 2014 (28,5\%). Já a decomposição da diferença entre os indicadores de desigualdade entre dois anos, a contribuição da educação para redução na variância do logaritmo dos salários corresponde a aproximadamente $35 \%$ em ambos os subperíodos.

Por sua vez, os fatores relacionados com a segmentação ocupacional, setorial e regional do mercado de trabalho explicaram o nível de desigualdade em pouco mais de $12 \%$ nos anos de 1995 e 2004, e $7,6 \%$ em 2014. Já a contribuição de tais variáveis sobre a redução da variância do logaritmo dos salários foi de $11,7 \%$ entre 1995 e 2004, e de 23,6\% entre 2004 e 2014. Dentre as variáveis desse grupo, destacam-se a contribuição do diferencial regional de salários e o diferencial ocupacional (formal-informal), sendo que este segundo foi negativo no subperíodo 1995-2004.

Fatores relacionados com a discriminação por gênero e raça tiveram contribuições para o nível de desigualdade observado em torno de 5,3\% em 1995, 3,7\% em 2004 e 3,1\% do nível de desigualdade observado nos anos considerados. A contribuição destes fatores para a redução da desigualdade variou bastante entre os dois períodos analisados, sendo de 13,3\% em 1995-2004 e de 6\% em 2004-2014.

Por fim, uma forte contribuição é apontada para fatores não observados. Na decomposição do nível de desigualdade em cada um dos anos, o termo residual apresentou contribuições de 43,5\% em 1995, 
44,3\% em 2004 e 52,3\% em 2014. Na decomposição da diferença, essa contribuição foi de quase 40\% em 1995-2004 e de $23,4 \%$ em 2004-2014.

Essa elevada contribuição do resíduo é bastante comum na literatura, sendo atribuída às variáveis não incorporadas ao modelo. Fields (2003) reporta um efeito residual em torno de $60 \%$ sobre o nível de desigualdade americano, entre 1979 e 1999. Também para a economia americana, Yun (2006) reporta um efeito residual de $77 \%$ no nível de desigualdade em 1979 e de até de 99\% na diferença de desigualdade entre 1969 e 1999.

A próxima subseção apresenta os resultados da síntese proposta por Yun (2006), em que o efeito preço e o efeito quantidade das variáveis explicativas da equação de salários são detalhados, aplicando diretamente a expressão [12].

\subsection{Decomposição da diferença em efeito preço e efeito quantidade- Yun (2006)}

A decomposição dos efeitos preço e quantidade permite uma análise mais acurada da mudança na desigualdade de renda no período analisado, ofertando intuições interessantes para o entendimento da dinâmica da distribuição dos salários. Considerando um atributo produtivo qualquer, o chamado efeito preço diz em quanto a mudança no retorno desse atributo (retorno da educação, por exemplo) afetou a variação da medida de desigualdade. Já o efeito quantidade diz em quanto uma mudança na quantidade observada (anos de estudo) impactou a mudança do indicador da distribuição salarial. A Tabela 6 apresenta os resultados da decomposição detalhada em efeito preço e efeito quantidade para cada variável explicativa considerada no modelo de salários. 
Tabela 6- Decomposição da variação da desigualdade em efeito preço e efeito quantidade.

Valores percentuais entre parênteses.

\begin{tabular}{|c|c|c|c|c|}
\hline & $\Delta$ Var. & 995-2004) & $\Delta$ Var. & 2004-2014) \\
\hline & & & & \\
\hline & Preço & Quantidade & Preço & Quantidade \\
\hline Total & $-0,1298$ & $-0,0046$ & $-0,1996$ & 0,0125 \\
\hline & $(96,6)$ & $(3,4)$ & $(106,7)$ & $(-6,7)$ \\
\hline Canital Human & $-0,048$ & 0,001 & $-0,115$ & 0,029 \\
\hline Capital Humano & $(35,57)$ & $(-0,37)$ & $(61,41)$ & $(-15,29)$ \\
\hline Educacão & $-0,0485$ & 0,0027 & $-0,0909$ & 0,0256 \\
\hline & $(36,09)$ & $(-2,01)$ & $(48,58)$ & $(-13,68)$ \\
\hline Fynoriância & 0,0014 & $-0,0013$ & $-0,0124$ & 0,0021 \\
\hline Expenericia & $(-1,04)$ & $(0,97)$ & $(6,63)$ & $(-1,12)$ \\
\hline & $-0,0007$ & $-0,0009$ & $-0,0116$ & 0,0009 \\
\hline Permanencia & $(0,52)$ & $(0,67)$ & $(6,20)$ & $(-0,48)$ \\
\hline Discriminacão & $-0,014$ & $-0,004$ & $-0,007$ & $-0,003$ \\
\hline & $(10,49)$ & $(2,75)$ & $(3,74)$ & $(1,60)$ \\
\hline Muther & $-0,0091$ & $-0,0028$ & $-0,0013$ & $-0,0025$ \\
\hline Tyluter & $(6,77)$ & $(2,08)$ & $(0,69)$ & $(1,34)$ \\
\hline Branco & $-0,005$ & $-0,0009$ & $-0,0057$ & $-0,0005$ \\
\hline & $(3,72)$ & $(0,67)$ & $(3,05)$ & $(0,27)$ \\
\hline Sogmontarãก & $-0,014$ & $-0,001$ & $-0,034$ & $-0,013$ \\
\hline Segmentaçao & $(10,71)$ & $(1,04)$ & $(18,12)$ & $(7,00)$ \\
\hline Setor & $-0,0083$ & $-0,001$ & $-0,0013$ & $-0,0031$ \\
\hline Setor & $(6,18)$ & $(0,74)$ & $(0,69)$ & $(1,66)$ \\
\hline Ocupacão & 0,009 & $-0,0001$ & $-0,0191$ & $-0,01$ \\
\hline vcupaçao & $(-6,70)$ & $(0,07)$ & $(10,21)$ & $(5,34)$ \\
\hline Reяi⿱̃⿻ & $-0,0151$ & $-0,0003$ & $-0,0135$ & 0,00 \\
\hline negrau & $(11,24)$ & $(0,22)$ & $(7,22)$ & $(0,00)$ \\
\hline Resídun & $-0,0535$ & & $-0,0438$ & \\
\hline & $(39,81)$ & & $(23,41)$ & \\
\hline
\end{tabular}

Fonte: Elaboração Própria. Microdados PNAD/IBGE (1995, 2004 e 2014).

Contribuições percentuais na diferença em Var.ln (y) são reportadas em parênteses.

De acordo com os resultados da decomposição, a mudança na estrutura salarial, dada pelo efeito preço, é o principal responsável pela redução na desigualdade de salários ao longo de todo o período analisado. As contribuições estimadas do efeito preço agregado para a redução na variância do logaritmo dos salários contabilizou 96,6\% entre 1995 e 2004, e superou os 100\% entre 2004 e 2014. Por sua vez, o efeito quantidade agregado apresentou uma contribuição pou- 
co significativa entre 1995 e 2004, e um efeito contrário à redução da desigualdade salarial entre 2004 e 2014. Características não observáveis também apresentaram uma contribuição importante para a redução da desigualdade, de $39,8 \%$, no primeiro período e de $23,4 \%$ no segundo.

Fatores relacionados ao capital humano dos trabalhadores foram determinantes para a dinâmica da desigualdade de rendimentos no período considerado. A partir da decomposição detalhada, o efeito preço associado às variáveis de capital humano respondeu por $35,6 \%$ da redução da desigualdade entre 1995 e 2004, e por 61,4\% entre 2004 e 2014. Com relação ao efeito quantidade associado a este conjunto de variáveis, tem-se que a contribuição deste fator se apresentou favorável à concentração de rendimentos no período 2004-2014.

Em qualquer um dos casos, destaque deve ser dado ao efeito da educação. Entre 1995 e 2004, a mudança na composição educacional da força de trabalho, captado pelo efeito quantidade, apresentou uma contribuição de $2 \%$ contrária à redução da desigualdade salarial. Já no período entre 2004 e 2014, esse efeito se amplia, indicando que, mantendo os demais fatores constantes, inclusive os retornos, a desigualdade de rendimentos medida pela log-variância teria aumentado quase $14 \%$. Esse comportamento se assemelha ao fenômeno "paradoxo do progresso" discutido em Bourguignon et al. (2005), que descreve uma situação em que o progresso em termos do crescimento da escolaridade ou uma maior equalização educacional pode gerar desigualdades na distribuição dos rendimentos do trabalho. Esse resultado é comumente atribuído à presença de convexidade nos retornos da educação. ${ }^{10}$

Por fim, os fatores associados à discriminação e segmentação também apresentaram uma maior contribuição em termos do efeito preço, mas com importância diferenciada em cada um dos períodos analisados. No que diz respeito à discriminação, destaca-se a redução nos diferenciais de salários por gênero, que apresentou uma contribuição mais significativa em 1995-2004. Quanto aos aspectos de segmentação, destacam-se a redução das disparidades regionais e as contribuições da segmentação ocupacional, entre setores formal e informal.

${ }^{10}$ Alejo (2012) aponta duas hipóteses para a relação entre educação e desigualdades salariais. Além da hipótese de convexidade, o autor avalia um postulado de heterogeneidade dos retornos educacionais. 


\section{Considerações finais}

Inspirado na importância dos rendimentos do trabalho para a redução na desigualdade de renda no Brasil ao longo da década de 2000, o presente estudo aplicou um modelo de decomposição de desigualdade baseado em regressões para contabilizar a contribuição de características individuais para a mudança na desigualdade salarial entre 1995 e 2014.

A principal contribuição da análise apresentada por esse artigo está na aplicação dos métodos de decomposição de Fields (2003) e Yun (2006), ainda pouco explorados na literatura nacional. A aplicação de tais métodos possibilita a decomposição de mudanças nas características produtivas dos trabalhadores (efeito quantidade) e dos retornos destas características (efeito preço), de forma simples e bastante intuitiva. Quanto aos resultados apresentados, estes confirmam algumas evidências já relatadas na literatura e apresentam novas evidências, principalmente quanto aos efeitos da educação para a dinâmica recente da distribuição de salários.

Os resultados indicam que as variáveis de educação, experiência e permanência no mesmo emprego contribuíram significativamente para a redução no indicador de variância do logaritmo dos salários, sendo as de maior relevância na explicação dos níveis de desigualdade observados e para a redução na desigualdade ao longo de todo o período considerado. Também foi possível verificar a contribuição de reduções nos diferenciais de rendimentos por gênero, raça e de acordo com a segmentação setorial, ocupacional e regional.

Os resultados da decomposição revelaram que a redução na desigualdade de salários pode ser explicada essencialmente por mudanças na estrutura salarial, ou seja, o chamado efeito preço. Destaca-se a contribuição das mudanças nos retornos educacionais, cujo efeito foi responsável por mais de $35 \%$ da redução da desigualdade de rendimentos entre 1995 e 2004, e quase 50\% da redução entre 2004 e 2014.

Já o efeito quantidade agregado contabilizou uma contribuição relativamente modesta no primeiro período (1995-2004) e contrária à tendência de queda da desigualdade no segundo período (20042014). Com base nos resultados da decomposição detalhada foi pos- 
sível observar que essa dinâmica é explicada, em grande parte, pelas mudanças na composição educacional da força de trabalho. O efeito quantidade associado à distribuição de escolaridade dos trabalhadores mostrou-se pernicioso quanto ao objetivo de redução da desigualdade. Esse resultado contrapõe-se às evidências até então apresentadas na literatura nacional, mas possui amparo em um fenômeno descrito como "paradoxo do progresso" discutido em Bourguignon et al. (2005). Trata-se de um resultado instigante e que deverá receber maior atenção em trabalhos futuros.

\section{Referências}

ALEJO, J.. Educación y Desigualdad: una metodología de descomposición basada en dos interpretaciones de laecuación de Mincer. Evidencia para Argentina. XLVII Reunión Anual de la Asociación Argentina de Economía Política, Trelew, Argentina, 2012.

AZEVEDO, J. P. Avaliando a significância estatística da queda na desigualdade no Brasil. In: BARROS, R. P.; FOGUEL, M. N.; ULYSSEA, G. (orgs). Desigualdade de Renda no Brasil: Uma Análise da Queda Recente. Brasília: Ipea, v. 1, 2007.

BARROS, R. P.; CARVALHO, M.; FRANCO, S.; MEDONÇA, R. Uma Análise das Principais Causas da Queda Recente na Desigualdade de Renda Brasileira. Texto para Discussão, n. 1.203. Rio de Janeiro: IPEA, ago. 2006.

, R. Determinantes da Queda na Desigualdade de Renda no Brasil. Texto para Discussão, n. 1.460. Rio de Janeiro: IPEA, jan. 2010.

BARROS, R. P. de; HENRIQUES, R.; MENDONÇA, R. Education and equitable economic development. Economia, v. 1, n. 1, jan. 2000.

BARROS, R.; FRANCO, S.; MENDONÇA, R. Determinantes Imediatos da Queda da Desigualdade Brasileira. In: BARROS, R. P.; FOGUEL, M. N.; ULYSSEA, G. (orgs). Desigualdade de Renda no Brasil: Uma Análise da Queda Recente. Brasília: Ipea, v. 2, 2007a.

BARROS, R. P.; FRANCO, S.; MEDONÇA, R. Discriminação e Segmentação no Mercado de Trabalho e Desigualdade de Renda no Brasil. Texto para Discussão, n. 1.288. Rio de Janeiro: IPEA, jul. 2007b. . A Recente Queda da Desigualdade de Renda e o Acelerado Progresso Educacional Brasileiro da Última Década. Texto para Discussão, n. 1.304. Rio de Janeiro: IPEA, jan. 2007c.

BARROS, R. P.; MENDONÇA, R. Os determinantes da desigualdade no Brasil. Texto para Discussão, n. 377. Rio de Janeiro: IPEA, 1995.

BLINDER, A. Wage Discrimination: Reduced Form and Structural Estimates. Journal of Human Resources, 8, 1973.

BOURGUIGNON, F. Decomposable Income Inequality Measures, Econometrica 47, 1979.

BOURGUIGNON, F., FERREIRA, F.H.G. e LUSTING, N.E. (eds). The Microeconomics of Income Distribution Dynamics. Washington, DC: World Bank and Oxford University Press; 2005.

BOURGUIGNON, F.; FOURNIER, M.; GURGAND, M. Fast development with a stable income distribution: Taiwan, 1979-94. Review of Income and Wealth, v. 47, n. 2, 2001.

CUNHA, M. S.; VASCONCELOS, M. R. Evolução da desigualdade na distribuição dos salários no Brasil. Economia Aplicada, Ribeirão Preto, v. 16, n. 1, 2012. 
DINARDO, J; FORTIN, N. M.; LEMIEUX, T. Labor Market Institutions and the Distribution of Wages, 1973-1992: A Semiparametric Approach. Econometrica 64, 1996.

FIELDS, G. S. Accounting for income inequality and its changes: A new method with application to the distribution of earnings in the United States. Research in Labour Economics, vol. 22, 2003.

FOGUEL, M. N.; e AZEVEDO, J. P. Uma decomposição da desigualdade de rendimentos do trabalho no Brasil, 1995-2005.In: BARROS, R. P.; FOGUEL, M. N.; ULYSSEA, G. (orgs). Desigualdade de Renda no Brasil: Uma Análise da Queda Recente. Brasília: Ipea, v. 2, , 2007.

HOFFMAN, R. Transferências de renda e a redução da desigualdade no Brasil e cinco regiões entre 1997 e 2004. Econômica, v. 8, n. 1, 2006.

HOFFMANN, R.; DE OLIVEIRA, R. B. The Evolution of Income Distribution in Brazil in the Agricultural and the non-agricultural Sectors. World Journal of Agricultural Research, v. 2, n. 5, 2014.

JUHN, C.; MURPHY, K. M., \& PIERCE, B. Wage Inequality and the Rise in Returns to Skill. Journal of Political Economy, v.113 1993.

MENEZES-FILHO, N.; FERNANDES, R.; PICCHETTI, P. Rising human capital, but constant inequality: the education composition effect in Brazil. Revista Brasileira de Economia, v. 60, 2006.

MENEZES-FILHO, N.; FERNANDES, R.; PICCHETTI, P.. Educação e queda recente da desigualdade no Brasil. In: BARROS, R. P.; FOGUEL, M. N.; ULYSSEA, G. (orgs). Desigualdade de Renda no Brasil: Uma Análise da Queda Recente. Brasília: Ipea, v. 2, , 2007.

MORDUCH, Jonathan; SICULAR, Terry. Rethinking inequality decomposition, with evidence from rural China. The Economic Journal, v. 112, n. 476, 2002.

PYATT, G., CHEN, C., FEI, J. The distribution of income by factor Components. The Quarterly Journal of Economics. 1980.

OAXACA, R. Male-Female Wage Differentials in Urban Labor Markets. International Economic Review, 14(3), 1973.

RAMOS, L. Desigualdade de rendimentos do trabalho no Brasil no período pós-real. Nota Técnica, IPEA, 2006.

RAMOS, L.; VIEIRA, M. L. Determinantes da Desigualdade de Rendimentos no Brasil nos Anos Noventa: Discriminação, Segmentação e Heterogeneidade dos Trabalhadores. Texto para Discussão, n. 803. Rio de Janeiro: IPEA, jun. 2001.

SHORROCKS, A, F. Inequality Decomposition by Factor Components. Econometrica, v. 50, n.1, January 1982.

SOARES, S. Análise de Bem-Estar e Decomposição por Fatores da Queda na da Desigualdade entre 1995 e 2004. Econômica, Rio de Janeiro, v.8, n. 1, 2006.

SOARES, F. V.; SOARES, S.; MEDEIROS, M.; GERREIRO, R. Programas de Transferência de Renda no Brasil: Impactos sobre a desigualdade. Texto para Discussão, n. 1.228. Brasília: IPEA, out, 2006.

YUN, M. Earnings Inequality in USA, 1969-99: Comparing Inequality Using Earnings Equations. Review of Income and Wealth, S.52, n.1, March, 2006. 